\title{
The quality evaluation of the ballastless track construction in the area of Bratislava tunnel no. 1
}

\author{
Libor Ižvolt ${ }^{1}$, Michal Šmalo, ${ }^{1, *}$, and Jana Malchová ${ }^{2}$ \\ ${ }^{1}$ Department of Railway Engineering, Faculty of Civil Engineering, University of Zilina, Univerzitna \\ 8215/1, SK-010 26 Žilina, Slovak Republic \\ ${ }^{2}$ Institute of Continuing Education, University of Zilina, Univerzitna 8215/1, SK-010 26 Zilina, \\ Slovak Republic
}

\begin{abstract}
The ballastless track design is the perspective for the construction of tunnels and bridge structures on the modernized track sections in Slovakia. Thanks to its indisputable advantages this construction is also used within the tunnel reconstructions. The Department of Railway Engineering and Track Management of the Faculty of Civil Engineering of the University of Zilina carries out the diagnostics of an experimental section with ballastless track construction in Bratislava tunnel No. 1 twice a year.
\end{abstract}

\section{Introduction}

The ballasted track is composed of rails, rail supports, rail fastening and ballast. The track superstructure design where the ballast function is substituted by the reinforced materials placed on the concrete supporting slab or the bituminous supporting slab is called the ballasted track [1], [2]. In general, the ballastless track structure is implemented especially on the high speed lines, the tracks with high traffic load and the modernized sections of the standard lines (operating speeds up to $160 \mathrm{~km} . \mathrm{h}-1$ ), respectively the tracks for higher speeds (operating speeds $160 \mathrm{~km} . \mathrm{h}-1<\mathrm{V} \leq 200 \mathrm{~km} . \mathrm{h}-1$ ) nowadays. The ballastless track structure is built particularly on the track sections conducted in tunnels because of properties of the foundation soil which does not observe any settlement. This ballastless track structure is also used on the bridges. Moreover, the usage of the ballastless track structure has a positive influence also on the amount of investment costs for the building of tunnel tube regarding the smaller tunnel section in case of its new construction resp. by elimination of the expensive tunnel widening (e.g. in case of its electrification on the existing lines) [3].

\footnotetext{
* Corresponding author: michal.smalo@fstav.uniza.sk
} 


\begin{tabular}{|ll|}
\hline Nomenclature \\
MSO & measurements before putting section into operation \\
PK & track superelevation $[\mathrm{mm}]$ \\
PO & operational measurement \\
QM & quality mark \\
QN & quality number \\
RK & track gauge [mm] \\
RP & velocity zone \\
SDV & standard deviation of variable \\
SL & alignment of left rail [mm] \\
SR & alignment of right rail [mm] \\
VL & rail top level of left rail [mm] \\
VR & rail top level of right rail [mm] \\
ZK & quasi-twist on a short base [mm. $\left.\mathrm{m}^{-1}\right]$ \\
ZR & change of gauge [mm.m $\left.{ }^{-1}\right]$ \\
ZSR & Railways of Slovak Republic \\
\hline
\end{tabular}

\section{The characteristics of the experimental section}

The experimental section in the area of Bratislava tunnel No. 1 is located from $\mathrm{km} 53.063$ to $\mathrm{km} 53.710$ the double track Devinska Nova Ves - Sturovo. The ballastless track structure of ÖBB-PORR type was built within the tunnel modernization realized over the period from October to December 2014 (reconstruction of the adjacent tunnel tube - of Bratislava tunnel No. 2 - was realized in the year 2009 and there was built the ballastless track structure with the Y-type sleepers in the reinforced concrete slab of SATO type) [1]. The aim of the modernization of Bratislava tunnel track No. 1 was the removal of the insufficient technical condition of the railway superstructure resulting from the complicated maintenance of the fastenings on the wooden sleepers (up to a half of their height built into the reinforced concrete slab) occurring in bad technical state (cracks and rotten material of the sleepers) and the removal of bad technical condition of the contact system caused by the water flowing through the vault into the tunnel [4].

The design of the track superstructure of Bratislava tunnel No. 1 is composed of the precast reinforced concrete slabs of ÖBB-PORR type that are monolithically joined to the invert vault of the tunnel tube. The reinforced concrete slabs have dimensions $4760 \times 2400$ x $160 \mathrm{~mm}$ and there are eight pairs of fastening points in the cross-distance $600 \mathrm{~mm}$ on each slab. The fastening points are dimensionally produced for the fastening system of UIC 60 E2 type in the gradient of the rail surface 1:40 and with the fastening Vossloh W 300-1. There are altogether 124 slabs of ÖBB-PORR type imbedded in the tunnel on the sanitized bottom part of the tunnel tube. There are imbedded steel clips with the diameter $20 \mathrm{~mm}$ and the length $300 \mathrm{~mm}$ into the bottom tunnel tube construction to fasten the level regulating concrete course and the invert of the tunnel.

In comparison to the monolithic ballastless track structure is the advantage of the construction system ÖBB-PORR in the possibility of damage elimination in the case of the occurrence of an accident (derailment). In this case the slabs can be individually replaced. The flexible layers, which are a part of every slab's equipment (the walls of technological holes and the bearing surface), enable with the use of special appliance and after applying sufficient force to raise up the slab and to separate it from the concrete sealing coat. After the realization of the repairs of the concrete sealing coat a new slab is built in and embedded into the concrete and the track can be put into operation within several hours. 
The ending of the ballastless track structure is in regard to the present state (track speed $60 \mathrm{~km} \cdot \mathrm{h}^{-1}$ ) composed of the combination of glued ballast and track skeleton with concrete sleepers of ZPSV type. The transition area in the vicinity of the Lamac portal in the length of $18.020 \mathrm{~m}$ is composed of 30 sleepers of BV 08 type with the fastening Vossloh W 14T. The track ballast of different thickness (from 100 to $350 \mathrm{~mm}$ ) is embedded on the top surface of the sub-ballast composed of $200 \mathrm{~mm}$ thick concrete slab. In the vicinity of Bratislava main station tunnel portal is the transition area placed directly behind the station head of the railway station Bratislava main station. In regard to the limited area conditions and a high track stiffness is the transition area realized in the length $5.592 \mathrm{~m}$ by means of seven concrete sleeper pieces with the fastening Vossloh W 14T and two pieces of wooden sleepers. The track ballast of size fraction $31.5 / 63 \mathrm{~mm}$ was in both transition areas glued in volume by the double compound epoxy resin Kryolit - the first stage was realized within the building-up (under the bottom surface of the sleepers) and the second stage was realized after one year of operation (in the space between sleepers and behind the sleeper) [4].

\section{Methods and means of the diagnostics of the track geometry}

The diagnostics of track geometry is carried out by measuring trolley $\mathrm{KRAB}^{\mathrm{TM}}$-Light. The measurement is referred to as continuous, but in fact, the data is recorded with the measuring step of $250 \mathrm{~mm} \mathrm{[2],} \mathrm{[5],} \mathrm{[6]:}$

- gauge deviation $R K$ (after calculating is also recorded change of gauge $Z R$ ),

- alignment of right rail $S R$ (after calculating is also recorded alignment of left rail $S L$ ),

- rail top level of right rail $V R$ (after calculating is also recorded rail top level of left rail $V L)$,

- track superelevation $P K$,

- quasi-twist on a short base (calculating to a quasi-twist on a base of $1.8 \mathrm{~m}$ long $-Z K$ 1.8 , on a base of $6.0 \mathrm{~m}$ long $-Z K 6.0$ and on a base of $12.0 \mathrm{~m}$ long $-Z K 12.0$ ),

- track distance.

- After the transmission of the measured data into the operating computer and after the defining of the tolerance there is following generated for the purposes of evaluation [6]:

- graph of the measured parameters of the track geometry,

- table of the local errors, i.e. the summary of the tolerance overrun,

- table of the track section evaluation which is based on the standard deviations and the quality numbers.

\section{The results evaluation of the diagnostics of the track geometry}

The results of the diagnostics are evaluated in terms of the rules in operation and the regulations of the railroads in Slovakia:

- STN 736360 Track Alignment Design and Track Geometry of Normal-gauge Tracks (1999) and Amendment 1 (2002), this is valid for the line tracks with the operating speed up to $60 \mathrm{~km} / \mathrm{h}$ including (i.e. for $R P$ 1) [5],

- Regulation ŽSR SR 103-7 (S) Measurement and Evaluation of Track Geometry by Measuring Trolley KRAB (in Slovak) (2008) [6].

The diagnostics of the track geometry was realized as [7]:

- the initial measurement before putting the construction into operation (signed MSO) executed on 29 April 2015,

- the first operational measurement (PO1) executed on 22 October 2015,

- the second operational measurement (PO2) executed on 11 April 2016. 
The measured parameters were evaluated according to the installation requirements for track parameters with the use of new material $(M S O)$, resp. according to the maintenance limits and the safety limits for velocity zone No. $1 / R P 1 /$ (table 1$)$.

The individual parameters evaluation of the track geometry is insured in the sectional track evaluation by elaboration of the standard deviations. These are calculated of the deviations from the central line which is computed of the dynamic component of the parameters of the track geometry $(S K, R K, P K, V K)$ in the zone of wave lengths of $1 \mathrm{~m}$ to $25 \mathrm{~m}$ measured after $250 \mathrm{~mm}$. The standard deviation $(S D V)$ expresses the course irregularity of the parameter of the track geometry in the evaluated section.

The state of the constructional track layout and the track geometry in the evaluated section is expressed by [6]:

- the sectional quality number $(Q M)$ of the individual geometric parameter $(S K, R K, P K$, $V K)$,

- the general quality mark $(G Q M)$ which serves as the evaluation of the track geometry in the evaluated track section as a whole,

- the tamping mark (TM) which is used to decide whether to use the tamping machine and it differs from $G Q M$ in that, that it does not include the track gauge influence $(R K)$ which is not repaired by the tamping machines,

- the quality number $(Q N)$.

The sectional evaluation is realized according to [6] and represented by:

- the quality number $(Q N)$ of the evaluated section which serves as the quality examination of the evaluation of the track geometry in the evaluated track section as a whole, and which is calculated of the standard deviations of the individual parameters of the evaluated section $(S K, R K, P K, V K)$. For the quality evaluation of the track geometry are specified the recommended values of the standard deviations of the individual parameters and quality numbers for the velocity zones. The limiting values of the standard deviations and the quality numbers for $R P 1$ are introduced in the table 2 ,

- quality marks $(Q M)$ of the individual geometric parameters $(S K, R K, P K, V K)$. The evaluation results according to the quality marks are the orientation and the additional evaluation and they are not obligatory for the state evaluation of the track geometry. The actions which are specified by the particular quality mark intervals have a recommending character (table 3).

Table 1. The parameters tolerance of the track geometry for velocity zone No. 1 [5].

\begin{tabular}{|c|c|c|c|c|c|c|c|}
\hline $\begin{array}{l}\text { Measured } \\
\text { paramete } \\
\text { r }\end{array}$ & \multicolumn{2}{|c|}{$\begin{array}{l}\text { Installation } \\
\text { requirements }\end{array}$} & \multicolumn{2}{|c|}{$\begin{array}{c}\text { Maintenance } \\
\text { limits }\end{array}$} & \multicolumn{2}{|c|}{ Safety limits } & Note \\
\hline \multirow[b]{2}{*}{$\mathrm{RK}(\mathrm{mm})$} & -2 & 3 & -4 & 10 & -5 & 20 & straight track \\
\hline & -2 & 3 & -4 & 26 & -5 & 35 & $\begin{array}{l}\text { transitioned } \\
\text { simple curve }\end{array}$ \\
\hline $\begin{array}{l}\mathrm{ZR} \\
(\mathrm{mm} / \mathrm{m})\end{array}$ & \multicolumn{2}{|c|}{3} & \multicolumn{2}{|c|}{4} & \multicolumn{2}{|c|}{5} & \\
\hline $\mathrm{PK}(\mathrm{mm})$ & -3 & 3 & -15 & 15 & -20 & 20 & \\
\hline $\begin{array}{l}\text { Measured } \\
\text { paramete } \\
\text { r }\end{array}$ & \multicolumn{2}{|c|}{$\begin{array}{l}\text { Limiting } \\
\text { values }\end{array}$} & \multicolumn{2}{|c|}{$\begin{array}{l}\text { Maintenance } \\
\text { limits }\end{array}$} & \multicolumn{2}{|c|}{ Safety limits } & Note \\
\hline \multirow{3}{*}{$\begin{array}{l}\mathrm{ZK}(1: \mathrm{n}) \\
(\mathrm{mm} / \\
\text { base) }\end{array}$} & \multicolumn{2}{|c|}{$1: 250(7.2 ; 4.0)$} & \multicolumn{2}{|c|}{$1: 250(7.2 ; 4.0)$} & \multicolumn{2}{|c|}{$1: 167(10.8 ; 5.99)$} & $\begin{array}{c}\text { on the } \\
\text { measuring base } \\
1.8 \mathrm{~m}\end{array}$ \\
\hline & \multicolumn{2}{|c|}{$\begin{array}{c}1: 320(18.8 \\
3.13)\end{array}$} & \multicolumn{2}{|c|}{ is not evaluated } & \multicolumn{2}{|c|}{$1: 250(24.0 ; 4.0)$} & $\begin{array}{c}\text { on the } \\
\text { measuring base } \\
6 \mathrm{~m}\end{array}$ \\
\hline & \multicolumn{2}{|c|}{ is not evaluated } & \multicolumn{2}{|c|}{ is not evaluated } & \multicolumn{2}{|c|}{$1: 333(36.0 ; 3.0)$} & $\begin{array}{c}\text { on the } \\
\text { measuring base } \\
12 \mathrm{~m}\end{array}$ \\
\hline
\end{tabular}




\begin{tabular}{|l|c|c|c|c|c|c|c|}
\hline $\begin{array}{l}\text { Measured } \\
\text { paramete } \\
\text { r }\end{array}$ & \multicolumn{2}{|c|}{$\begin{array}{c}\text { Relative } \\
\text { installation } \\
\text { requirements }\end{array}$} & \multicolumn{2}{|c|}{$\begin{array}{c}\text { Relative } \\
\text { maintenance } \\
\text { limits }\end{array}$} & \multicolumn{2}{|c|}{$\begin{array}{c}\text { Relative safety } \\
\text { limits }\end{array}$} & Note \\
\hline $\begin{array}{l}\text { VL, VP } \\
(\mathrm{mm})\end{array}$ & -4 & 4 & -15 & 15 & -20 & 20 & - \\
\hline $\begin{array}{l}\text { SL, SP } \\
(\mathrm{mm})\end{array}$ & -5 & 5 & -15 & 15 & -20 & 20 & - \\
\hline
\end{tabular}

Table 2. The parameters tolerance of the track geometry for RP1 [6].

\begin{tabular}{|c|c|c|c|c|c|c|c|}
\hline \multicolumn{4}{|c|}{ Installation requirements } & \multicolumn{4}{|c|}{ Safety limits } \\
\hline $\mathrm{SDV}_{\mathrm{SK}}$ & $\mathbf{S D V}_{\text {RK }}$ & $\mathbf{S D V}_{\mathbf{P K}}$ & $\mathbf{S D V}_{\mathrm{VK}}$ & $\mathbf{S D V}_{\text {SK }}$ & $\mathbf{S D V}_{\text {RK }}$ & SDV $_{\mathbf{P K}}$ & $\mathbf{S D V}_{\mathbf{V K}}$ \\
\hline 1.5 & 1.5 & 1.8 & 2.0 & 2.7 & 2.9 & 2.9 & 3.4 \\
\hline \multicolumn{4}{|c|}{ QN } & \multicolumn{4}{|c|}{ QN } \\
\hline \multicolumn{4}{|c|}{4.1} & \multicolumn{4}{|c|}{7.2} \\
\hline
\end{tabular}

Table 3. The scale of quality marks (QM) according to quality section evaluation [6].

\begin{tabular}{|c|c|c|}
\hline $\begin{array}{c}\text { Interval of } \\
\text { quality marks }\end{array}$ & $\begin{array}{c}\text { Verbal assessment section according to the quality } \\
\text { mark }\end{array}$ & $\begin{array}{c}\text { Colour of the quality } \\
\text { mark in printed } \\
\text { output }\end{array}$ \\
\hline $0<Q M \leq 2$ & state of track geometry is satisfactory in section evaluated & no colour marking \\
\hline $2<Q M \leq 3$ & $\begin{array}{c}\text { it is recommended to design the repair of track geometry in } \\
\text { the section evaluated into maintenance work plan }\end{array}$ & green colour \\
\hline $3<Q M<4$ & $\begin{array}{c}\text { it is recommended to perform the repair of track geometry } \\
\text { in the section evaluated to the nearest inspection }\end{array}$ & violet colour \\
\hline $4 \leq Q M \leq 6$ & $\begin{array}{c}\text { it is recommended to perform immediate measures in the } \\
\text { section evaluated to ensure the safety of operation }\end{array}$ & red colour \\
\hline
\end{tabular}

\section{The quality of the diagnosed sections}

Nowadays the results of the initial measurement, the first operational measurement and the second operational measurement are available before putting the section into operation. There were executed repair works by the builder with no provided records after the execution of the initial measurement. There was carried out an exchange of two reinforced concrete slabs on the Bratislava main station tunnel portal before the second operational measurement. Both slabs were damaged by the derailment at the switch No. 59 .

In regard to the curve parameters the whole section is qualified according to the rules for the straight sections (regarding the maintenance tolerance and the safety limits of the parameter $R K$ ).

There were identified 10 local errors within the initial measurement before putting the construction into operation (4 errors out of them are classified as irrelevant errors). There were no local errors diagnosed within the operational measurements after the execution of the repair works [7].

The quality mark values of the individual evaluated parameters are presented in the Fig. 1 . The limiting values indicating the impaired section state are according to the table 3 the values $2<Q M \leq 3$. In this case, in the evaluated track section is recommended to design the repair of track geometry in the section evaluated into maintenance work plan. In the intervals $3<Q M<4$, where is in the evaluated section recommended to perform the repair of track geometry in the section evaluated to the nearest inspection and $4 \leq Q M \leq 6$, which indicates the infrastructure provider the recommendation to execute the immediate measures to ensure the operation safety. In the last two intervals were no quality mark values detected for any of the parameters of the track geometry.

The quality mark of the geometric parameter alignment of right rail $Q M_{S K}$ (after calculation also of left rail) was in the interval $2<Q M_{S K} \leq 3$ within the initial measurement 
(the recommendation to design the repair of track geometry in the section evaluated into maintenance work plan). After execution of the repair works the quality mark values decreased to the interval $0<Q M_{S K} \leq 2$ (the state of track geometry is satisfactory) in both realized operational measurements. The quality marks of the other geometric parameters gauge deviations, superelevations and the rail top level of right rail (after calculation also the left) line were by all measurements in the interval $0<Q M \leq 2$ (the state of the track geometry is satisfactory in the evaluated track section) [7].

The quality numbers are presented in the Fig. 2. The quality number from the initial measurement (2.08) did not overrun the limited value specified for the installation requirements and the quality numbers from the first operational measurement (1.97) and the second operational measurement (1.97) did not overrun the values of the safety limits. The repair works executed before the first operational measurement improved the quality of the ballastless track and after the execution of the second operational measurement the quality number value steadied [4].

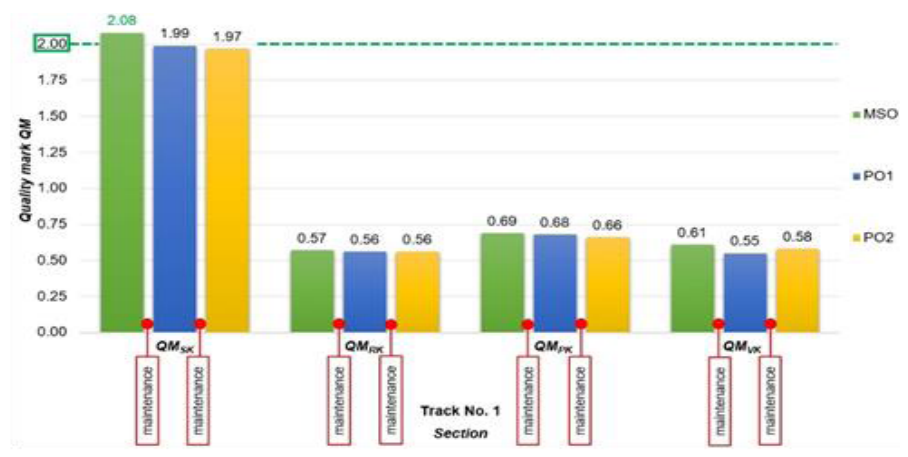

Fig. 1. Quality marks QM.

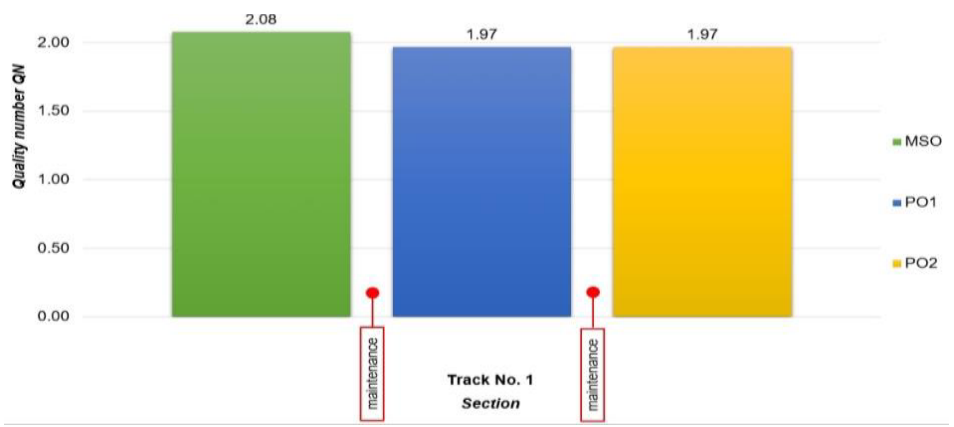

Fig. 2. Quality numbers QN.

The paper contains partial results of the grant VEGA 1/0597/14"Analysis of methods used to measure the unconventional railway track construction from the point of view of accuracy and reliability".

\section{References}

1. L. Izvolt, M. Smalo, Civ. and Env. Eng. 10(2), 78-93 (2014)

2. ZSR SR 103-8 (S) General Requirements for the Design, Construction, Repair, Maintenance and Acceptance of Construction Repair and Maintenance Works on the Slab Track Construction (GR ZSR, 2012) 
3. J. Sestakova, Civ. and Env. Eng. 11(1), (2015)

4. L. Izvolt, J. Sestakova, M. Smalo, Proc. of Sem. Res. for Railway Infr.Const., 9-10 March Decin, Czech Republic., 98-110 (2016)

5. STN 736360 Track Alignment Design and Track Geometry of Normal-gauge Tracks, and Amendment 1 (SÚTN, Bratislava, 2002)

6. ZSR SR 103-7 (S) Measurement and Evaluation of Track Geometry by Measuring Trolley KRAB (GR ZSR, 2008)

7. L. Izvolt et al., Monitoring of Transition Areas in Bratislava Tunnel, Track No. 1 of Line Devinska Nova Ves - Sturovo - 1st and 2nd Stage (KZSTH SvF: University of Zilina, Zilina, 2015) 